\title{
Fighting Forest Fires With Mechanical Equipment
}

Reprinted by Permission from WATSON, JACK \& CO. LTD.

The following extract is taken from a paper read by $\mathrm{Mr} . \mathrm{H}$. C. Johnson, Fire Inspector, Board of Railway Commissioners for Canada, at a Forest Protection Meeting convened by the Canafian National Railways at Toronto, Ontario during the month of January, 1925.

"No forest protection service is of value unless it is prepared and ready to meet the situation when fires occur. All such organizations should have at their command the most modern up-to-date proven methods for quickly extinguishing fires, once they are reported. The most energetic use of the old-style methods of fighting forest fires in conjunction with present-day advanced methods of detection and reporting, do not by any means suffice.

"Water has been the natural enemy of fire for probably a longer time than fire has been dangerous to man. There have been a great many fires fought by men with nothing better than shovels, which could have been quickly extinguished if water could have been used. Ten years ago mechanical equipment with which to fight forest fires was unheard of in Canada. The lack of some more potent fire-controlling force than mere man power was evident, and led to the development of forest firefighting apparatus, in order that water could be more effectively used on somewhat parallel lines to City Fire Department apparatus.

"As a means to this end, there had to be an idea. The idea was to extinguish forest fires by pumping water on them in much the same way as in our cities and towns, first to bring the fire under control, and then completely to drown it out. A development of this idea was to secure a light-weight power pump that could be transported in forested territory, capable of delivering water through a line of fire hose to considerable heights and distances. In order to reach the fire, it was proposed, when necessary, to use two or more pumps in finally reaching the fire; also, by using siamese connections, to attack a fire at more than one point by laying two or more lines of hose from one pump. In other words, by the aid of power pumps, fire nozzles, siamese connections, and canvas tanks, the fire-fighter was to be given effective means of using water to extinguish forest fires.

"The idea, however, did not gain ground very fast, not because it was not recognized that water could be used to great advantage in extinguishing fires, but because it was not considered posible to design apparatus that could be transported in forest territory, and at the same time be of practical value."

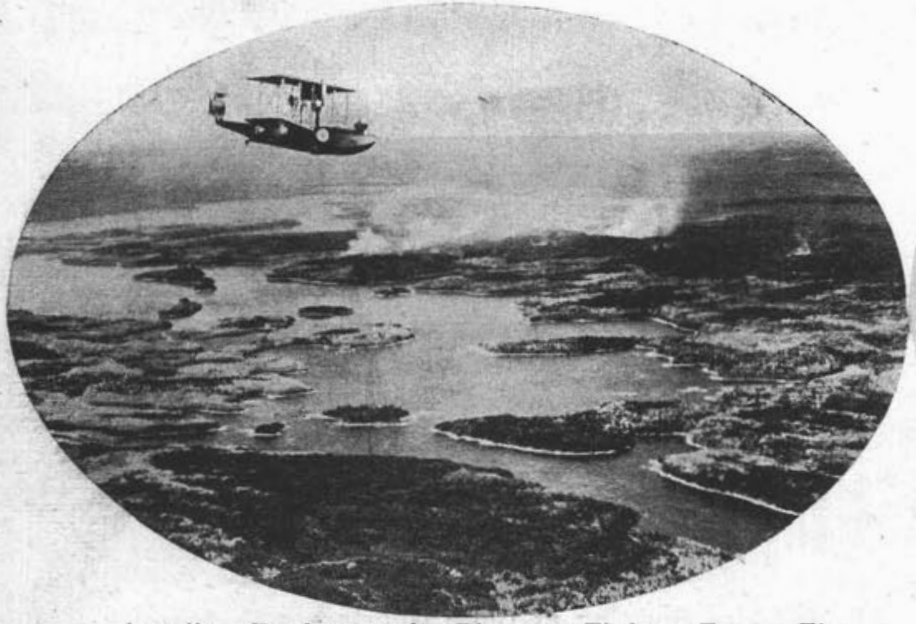

Landing Equipment by Plane to Fight a Forest Fire.
The weakest point in the science of forest protection has been the extinguishing of fires. Where and how fires will occur, their origin, how they are to be discovered, reported, and got to, has all been worked out to a degree of perfection; but for some reason little thought was given to the science of extinguishing forest fires. Strange to say, "fire suppression" for some reason was the last field of activity to receive attention. Presumably, it was taken for granted that the ranger and the lumberjack were natural firefighters, and could be depended upon in some mysterious manner to take care of the suppression end of the game. But it did not quite work out the way it was expected, with the result that fires continued to burn up the forests.

Out of the theory outlined above by Mr. Johnson, was evolved the greatest single factor in the progress made towards controlling the forest-fire situation during the past decade-"The Forest Fire Pump." Its successful introduction has been the result of years of study and exhaustive experiments. Not only have the pumping units been vastly improved but their application in the field has also received a great deal of attention, in order to ascertain their range and value, with the result that, to-day, mechanical apparatus in the form of powerful light-weight, Evinrude gasoline-motor-driven pumps, together with hose and accessories, have been designed especially to meet forest conditions. These outfits have been tested and proved, and are now in service from one end of Canada to the other. Such equipment and its application is a triumph of Canadian Forest Protection Service; and in the hands of properly trained fire-fighters, assures dependable forest fire protection, since it is now possible to attack and extinguish forest fires in a modern scientific manner at a fraction of the cost and time over the old chaotic methods. In comparison with the past, the efficiency to-day of any forest protection service depends upon the character and dependability of the fire-fighting equipment furnished the firefighters. Experienced fire-fighters maintain, and have repeatedly proved, that one reliable forest-fire pump will do as much effective work on a fire line as a crew of twentyfive men working with hand tools. Fire-fighters equipped only with ordinary hand tools are lucky indeed to control a fire; but by employing forest fire pumps, they can not only control but completely drown a fire out.

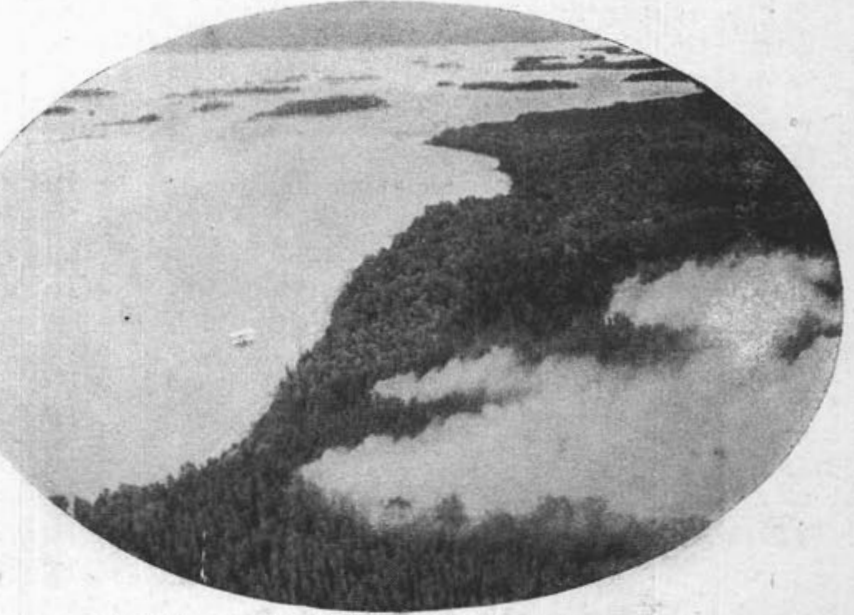

Sighting a Forest Fire-R C. A. F. in Action 


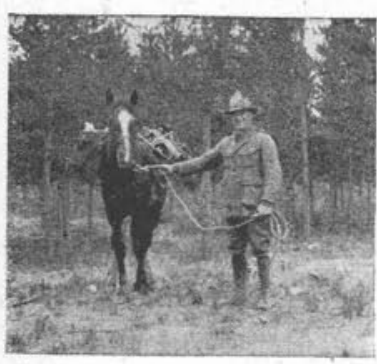

A Pack Horse with Pump Outfit

The following is a brief description of the manner in which mechanical equipment is now employed to suppress forest fires:

Preparation.-At district headquarters emergency crews of from four to six men, trained in the handling of pumps and hose, are held in readiness to proceed at a moment's notice to the scene of a fire. The fire-fighting equipment of these crews, consisting of axes, shovels, power pumps and hose, water bags and hand pumps, gasoline, food supplies, blankets and tent, are already made up into convenient packs, and stored ready for use.

Action.-The emergency crew having arrived at the fire, they immediately ascertain the location of the nearest water supply; this found, the power pump is at once brought into action. Suction hose is connected, discharge hose lines laid, and the fire attacked at one or more points. Quick action at the start, before the fire has had a chance to become large, may mean all the difference between having to fight a small fire or a conflagration. In attacking the fire, it is either drowned out by playing a stream of water directly onto it, or else the inflammable material lying in the path of the flames is wetted down to such an extent that the fire on reaching this point either dies out, owing to the wet state of the forest, or else its heat and progress is so retarded as to allow the fire-fighters to approach closer and finally drown it out. The quantity of water required to check a forest fire is very small, provided the supply be constant, and its application along the flanks and front of a fire is made quick and easy.

Hose.-One-and-a-half inch unlined linen hose put up in one-hundred foot lengths, has been found the most satisfactory discharge hese for this purpose, with nozzles having interchangeable discharge tips, and also especially designed tips to throw spray streams. For drowning out below-thesurface fires in dry muskegs, especially designed perforated pipe nozzles are used. These enable the fire-fighter to get at a fire several feet below the surface, or to create a wet trench in order to cut off a burning area.

Relay System.-In the case of fires too far away from supply for one pump to reach, what is known as the "relay water, or burning at elevations too high above the water system" is employed. This consists of putting into action No. 1 pump at the nearest water supply, and delivering water, through the longest line of hose possible, into a portable canvas tank. In fairly level country, the standard Evinrude, if necessary, is capable of delivering water to a distance of 7000 feet and to an elevation 250 feet above the water supply. A light twin pump then relays the water from the canvas tank directly onto the fire, or else into a second canvas tank placed at some distance ahead. Fires have been successfully fought in this manner where the water has had to be relayed several times in order to reach them. In one case, a canvas tank was used at the end of the first relay, a canoe at the end of the second, and a hole dug in the ground, with a tent thrown in to hold the water, was used at the end of the third relay. In spite of the distance, the fire-fighters got a good stream of water onto the fire and put it out.

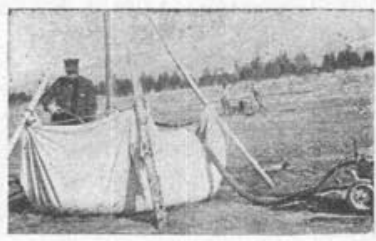

A Relay Water Tank

Siamese Uses.-In order to attack a fire at one or more points using these connections, several lines of hose can be operated from one pump. The main stream from the pump can be split into two streams, and the fire attacked on two sides simultaneously. An actual case illustrating the value of Siamese connections, oceurred during the late fire season in extremely mountainous country. At this fire, the use of Siamese connections enabled the firefighters to attack the fire simultaneously at eight different points, using one pump. The plan of attack required the use of seven Siamese connections, the first one being used some 400 feet from the pump to the split the main stream into one right-hand and one left-hand branch. The right-hand branch was then siamesed 700 feet from the pump into four streams, each being 300 feet in length. The left-hand line was treated in exactly the same manner. This fire was approximately eleven hundred feet distant from and some 200 feet elevation above, the water supply.

Hand Pumps.-Immediately on arrival at a fire one or two men equipped with water bags and hand pumps can frequently do valuable work in preventing the fire spreading, by employing this character of equipment. These water bags are carried on the back in the same manner as a pack sack, and have capacity of from five to seven gallons.

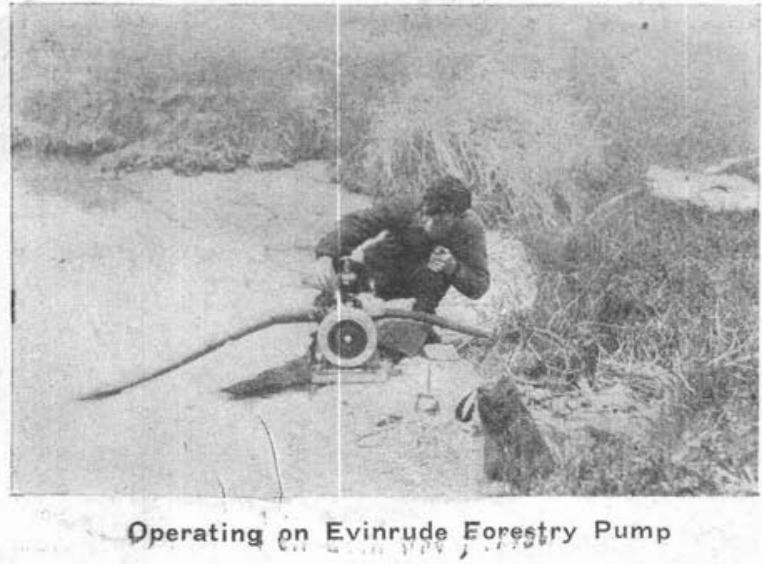

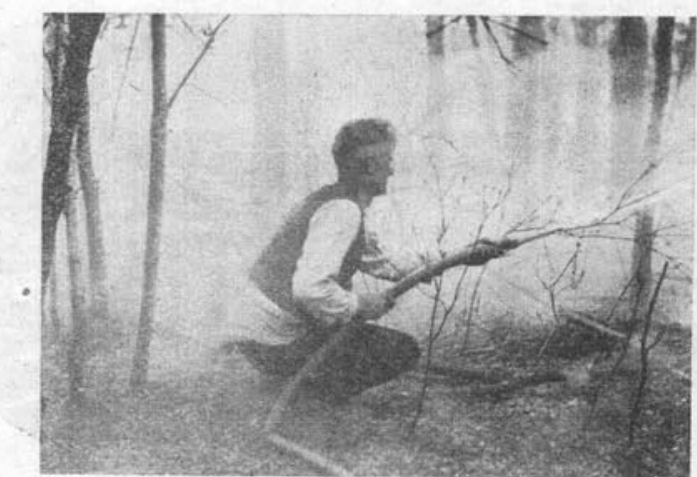

Forest Fire Fighting at Close Quarters with Forestry Pumps 
Attached to the bag by a short piece of rubber hose is a powerful hand pump, from which a solid stream can be thrown a distance of 50 to 60 feet. If desired, the nozzle can be changed and a spray thrown. Just as soon as the power pumps get into action, the men with the hand pumps can quickly refill their water bags from the hose lines and proceed to put out spot fires starting up ahead of the main fire, as also assisting to extinguish the main blaze by killing fresh outbreaks along the flanks.

Aeroplane Transportation.-Many instances throughout the Dominion are on record of the power pumps, hose and accessories having been transported to forest fires by aircraft. For this work, Evinrude pumps weighing as low as 48 pounds have been designed. These light-weight pumps are also intended to be used in mountainous country, where transportation is a serious problem. These small outfits are also used for relaying water onto a fire, using two or three of them to pump out of one canvas relay tank into which one of the larger pumps, possibly located a mile or more away, is delivering water.

Smoldering Fires.-The erroneous reporting of fires being out, after they have been brought under control, has cost Canada many square miles of valuable forest wealth, due to secondary outbreaks after the fire-fighters have retired. By using pumps, after the fire has been brought under control, the smoldering burned-over area if not too large, can be well drenched with water, or the edges of the fire swept area can also be well wet down and a pump or pumps kept in readiness to suppress any fresh outbreak. No fires is out until the last spark is extinguished.
Fire Lines.-By using power pumps, the fire-fighters employing two or three lines of hose, throwing from 25 to 70 gallons of water per minute, can quickly create a fire line by wetting down a strip of vegetation ahead of the on-coming fire. This was actually carried out by fire-fighters of the Ontario Forest Service, and the town of Foleyet was saved from certain destruction. The flames on reaching this wet-down strip of vegetation, naturally die down, and are then either extinguished or can be quickly drowned out by the constant stream of water flowing from the hose lines. and directed in any direction desired by the fire-fighters.

Slash Burning.-The presence of slash and inflammable dèbris in or adjacent to forests, constitutes the greatest menace from fire. Accumulations of this character make it most difficult to prevent, control, and extinguish fires. With the introduction of power pumps and hose lines, water bags and hand pumps, the risk of the fire escaping control during slash burning operations, as well as the cost of such work, has been reduced to a minimum. When such areas are to be burned, to safeguard the operation, a force of men equipped with power pumps, hose, water bags and hand pumps, should be on hand ready to suppress quickly at any point where the fire shows signs of getting beyond control. Morale - The essential equipment of the forest fire-fighter is that which will give him confidence in his ability to control and finallv extinguish fire. The Evinrude forest-fire pump does this. Good morale is on half of the battleEvinrude pumps, the other half. With both in cooperation, the Forest Fire ceases to be what, up to now, it has been - unconquerable. 